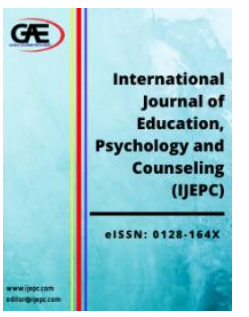

\author{
INTERNATIONAL JOURNAL OF \\ EDUCATION, PSYCHOLOGY \\ AND COUNSELLING \\ (IJEPC) \\ www.ijepc.com
}

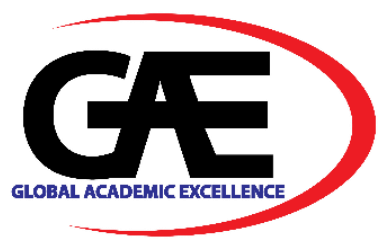

\title{
THE RELATIONSHIP BETWEEN ETHNOCULTURAL EMPATHY AND ORGANIZATIONAL CITIZENSHIP BEHAVIOR (OCB) AMONG PUBLIC SERVANTS IN SABAH
}

\author{
Razima Hanim Osman ${ }^{1 *}$, Mariny Abdul Ghani ${ }^{2}$, Norzaliza Alis ${ }^{3}$ \\ $1 \quad$ Faculty of Education and Psychology, Universiti Malaysia Sabah, Malaysia \\ Awang Had Salleh Graduate School, Universiti Utara Malaysia, Malaysia \\ Email: razima@ums.edu.my \\ 2 School of Applied Psychology, Social Work and Policy, Universiti Utara Malaysia \\ Email: mariny@uum.edu.my \\ 3 School of Applied Psychology, Social Work and Policy, Universiti Utara Malaysia \\ Email: nzaliza@uum.edu.my \\ Corresponding Author
}

\section{Article Info:}

Article history:

Received date: 01.09.2021

Revised date: 14.09 .2021

Accepted date: 23.09.2021

Published date: 30.09 .2021

\section{To cite this document:}

Osman, R. H., Abdul Ghani, M/, \& Alis, N. (2021). The Relationship Between Ethnocultural Empathy And Organizational Citizenship Behavior (OCB) Among Public Servants In Sabah. International Journal of Education, Psychology and Counselling, 6 (42), 469-481.

DOI: $10.35631 /$ IJEPC.642038

This work is licensed under CC BY 4.0

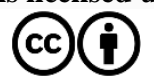

Abstract:

Organizational citizenship behavior (OCB) throughout literature provides evidence that benefits both employees and the organizations in terms of increasing the level of employees' well-being, work satisfaction, customers' satisfaction as well as the quality of work performance. Hence, it is important to understand the possible reasons behind the occurrence of OCB to increase the likelihood of employees engaging in OCB. Based on the prosocial motivational concept, empathy is the main motivator to helping behaviors thus open up the possibility of linkage between empathy and extra-role behaviors such as OCB. Moreover, this linkage is important for public employees especially those who are working in organizations that have multi-ethnic employees as well as providing services to meet vast societal needs and demands. The present article set out to examine the relationship between ethnocultural empathy and OCB among public employees in Sabah. A crosssectional survey was used to gather a response of 213 public employees who are working in the Jabatan Pendaftaran Negara Negeri Sabah (JPN) based on the selected districts in Sabah. Results showed positive relationships between organizational citizenship behavior-individual (OCBI) with empathic awareness (EA) dimensions. Results also showed positive relationships between organizational citizenship behavior-organization (OCBO) with empathic feeling and emotion (EFE). By focusing on the aspect of culture in empathy such as ethnocultural empathy can help researchers to understand how culture influences the cognition and emotions of individuals to understand other people's experiences especially those who have a different cultural and 


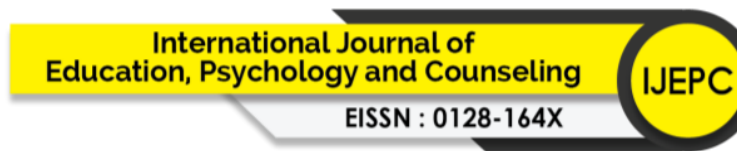

Volume 6 Issue 42 (September 2021) PP. 469-481

DOI 10.35631/IJEPC.642038

ethnic background. Apart from that, the concept itself strengthens the ability to understand the thinking and feeling of others in their cultural context thus increases the likelihood to perform extra-role behavior such as OCB.

Keywords:

Organizational Citizenship Behavior (OCB), Ethnocultural Empathy, Public Employees

\section{Introduction}

Organizational citizenship behavior (OCB) is one of the variables in organizational psychology research that have the same weight of importance similar to formal working behavior. This is due to its contribution that has proven to bring the organization to function effectively. Previous researches have shown that OCB benefits both employees and the organizations by increasing the level of employees' job satisfaction, psychological well-being, productivity and, quality of work as well as increased customer satisfaction (Basu, Pradhan, \& Tewari, 2017; Lavy \& Littman-Ovadia, 2016; Noorlaila Yunus \& Cairul Azwa Azimi, 2016; Subramaniam Sri Ramalu \& Zulhusni Mohamad Rashid, 2016). The key factor in OCB that aids organizations to success are the behavior itself in which is a form of discretionary actions that act upon personal choice moreover, beyond the prescribed behaviors stated in the job descriptions (Organ, 1997). OCB is not a compulsory behavior for the employees to engage in as the actions are considered as spontaneous behaviors which indirectly supporting existing formal behaviors.

Employees with OCB are considered as one of the important assets to the organizations due to its positive contributions towards organizational efficiency and employees' well-being. In fact, based on the enrichment-based perspective, OCB can influence the feeling of vigor and sense of meaningfulness in a job where these two feelings lead to positive well-being among employees (Lam, Wan \& Roussin, 2016). For these reasons, the OCB needs to be nourished among employees especially those who are working in public organizations as the nature of these organizations is to provide a variety of services that cater to societal needs and demands. Furthermore, the public nowadays are more attentive and aware of their rights by demanding more transparency processes and decision-making procedures made by the public organizations and government in their services (Ibrahim, Aziz Amin, Ghani Hashim \& Salleh, 2015). As dealing with the demand for jobs, the tendency of having emotional exhaustion has been reported among public employees (Raman, Sambasivan \& Kumar, 2016). This is contradictory to the feeling of satisfaction in work as well as positive well-being. Therefore, it is essential for public organizations to strengthen the social system within the organization by engaging in OCB.

For this reason, it is important to search for possible factors that influence OCB to occur among employees what's more to increase its occurrence in the organizational setting. Empathy is seen as one motivator to help others in need (Batson, Duncan, Ackerman, Buckley \& Birch, 1981). Based on the empathy-altruism hypothesis, empathy in general can leads to altruistic/helping behavior (Batson, et. al., 1981). As Organ (1997) mentioned that OCB is a discretionary behavior in which the behavior is produced based on the spontaneous act to help others in an organizational setting therefore, it is possible to have the linkage between empathy and OCB. In addition, empathy is a crucial element in professional service especially in public services 


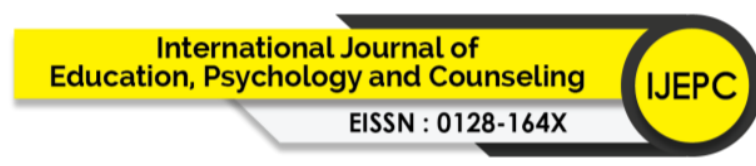

Volume 6 Issue 42 (September 2021) PP. 469-481

DOI 10.35631/IJEPC.642038

where the public employees provide services to the society regardless of different backgrounds, ethnicity, and traditions especially in Malaysia. As Rasoul, Eklund, and Hansel (2011) mentioned that empathy without having the knowledge or experience with people from different ethnic groups may interfere with the helping behaviors thus increasing the level of unsatisfying delivery of services among professionals. Therefore, the concept of empathy in culture needs to be explored and examined with the relations to OCB.

\section{Empathy and Helping Behaviour}

The connection between empathy and altruism/ helping behavior can be traced back to Batson's empathy approach whereby empathy is considered as the main motivator in helping others in need (Batson, Duncan, Ackerman, Buckley \& Birch, 1981). With attention to explain the motivation in helping others, Batson and colleagues (1981) justified the prosocial motivation by explaining the empathy-altruistic hypothesis approach. They further explained that motivation which is associated with the feeling of empathy for others in need was altruistic as the observer who has a high degree of empathy would help regardless of the difficulty level of the situation (Batson, et. al., 1981; Batson \& Shaw, 1991). In fact, McNeely and Meglino (1994) supported the discussion made by Batson and colleagues where they found that empathy and the value of concern for others were the antecedents for prosocial behaviors directed to an individual.

In this world beyond boundaries, people from various ethnic and cultural groups come in contact with each other on a daily basis in a variety of situations. Good social interaction between people from different cultural backgrounds is needed as this interaction may help to smooth the delivery of helping behavior. It is therefore important to consider how misunderstandings can arise in both informal interaction and professional's interaction with clients (e.g., psychologists, social workers, nurses, doctors, lawyers, teachers, and police officers) (Rasoal, Eklund \& Hansen, 2011). Hence, the concept of ethnocultural empathy plays a central role in social interaction among people with different cultures and ethnicity.

The study of empathy in culture have been conducted by previous researchers using different terminological terms such as group empathy (Sirin, Valentino \& Villalobos, 2016), empathic multicultural awareness (Junn, Morton \& Yee, 1995), and ethnocultural empathy (Wang, Davidson, Yakushko, Savoy, Tan \& Bleier, 2003). The term of ethnocultural empathy came to existence by researchers who described it as one of the abilities that can be learned to understand people with different ethnic backgrounds regarding the way they think, feel, and behave (Wang, Davidson, Yakushko, Savoy, Tan \& Bleier 2003; Wei, Li, Wang \& Ko, 2016). According to Wang, and colleagues (2003), there are three characteristics that explained ethnocultural empathy in detail. The first characteristic was intellectual empathy which refers to the ability to understand other ethnic groups' thinking and feeling (Wang et al., 2003). The second characteristic was the empathic emotions in which the attention was given to the feeling of a person based on other ethnic groups' point of view (Wang et al., 2003). The last characteristic was the communicative empathy whereby this component refers to the expression from the first and the second characteristics (intellectual empathy and empathic emotions) and the medium of expression are through words and actions (Wang et al., 2003).

Based on the literature, this study proposed the following hypothesis: 


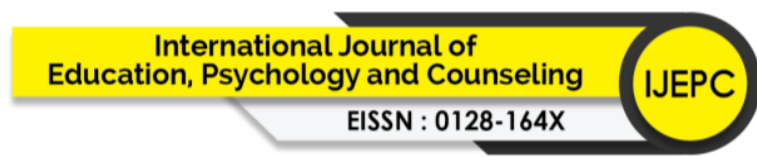

Volume 6 Issue 42 (September 2021) PP. 469-481

DOI 10.35631/IJEPC.642038

Hypothesis 1: There is a relationship between ethnocultural empathy dimensions (empathic feeling\& expression, empathic perspective-taking, empathic awareness, and acceptance of cultural differences) with OCBI.

Hypothesis 2: There is a relationship between ethnocultural empathy dimensions (empathic feeling\& expression, empathic perspective-taking, empathic awareness, and acceptance of cultural differences) with OCBO.

Therefore, this paper examines the relationship between the concept of empathy in culture (ethnocultural empathy) and OCB among public employees.

\section{Method}

\section{Research Design}

This study used a cross-sectional survey design where quantitative measures had been applied using statistical analyses to obtain the results in a specific time frame. The data was gathered via a questionnaire survey as it is a standard method used in getting a response from a large number of people and yet it can specify and focuses on the variables that need to be measured. Moreover, the questionnaire can be personally administered to a group of respondents to establish rapport and to assure a 100 percent response rate (Cavana, Delahaye \& Sekaran, 2001).

\section{Sample}

Using the sample size calculator online in the website, by calculating 5\% margin error and 95\% of confidence level, the recommendation of sample size for the population of 469 JPN's public/ civil employees in Sabah is 212 samples (Sample Size Calculator by Raosoft, 2017). Apart from that, based on the table provided by Krejcie and Morgan (1970), the estimation of the sample size of that particular population is $210-214$. Therefore, this study gathered samples of 213 of Sabah JPN's public/ civil employees.

\section{Instruments}

\section{The Scale of Ethnocultural Empathy (SEE)}

The Scale of Ethnocultural Empathy (SEE) was developed by Wang Davidson, Yakushko, Savoy, Tan, and Bleier, (2003) to measure four dimensions of ethnocultural empathy: -

(1) Empathic Feeling and Expression dimension - with 12 items relate to thoughts, feelings, words, and actions towards different ethnicity, for example, "When I know my friends are treated unfairly because of their racial or ethnic backgrounds, I speak up for them."

(2) Empathic Perspective Taking dimension - measured by five items that relate to understanding the emotions of people with different ethnicity, for example, "It is easy for me to understand what it would feel like to be a person of another racial or ethnic background other than my own."

(3) Acceptance of Cultural Differences dimension - with 5 items that measure acceptance and valuing others cultural traditions, for example, "I feel irritated when people of different racial or ethnic background speak their language around me." and

(4) Empathic Awareness dimension - measured by 4 items in terms of awareness/ knowledge and understanding of other ethnicities, for example, "I recognize that the media often portrays people based on racial or ethnic stereotypes.". 


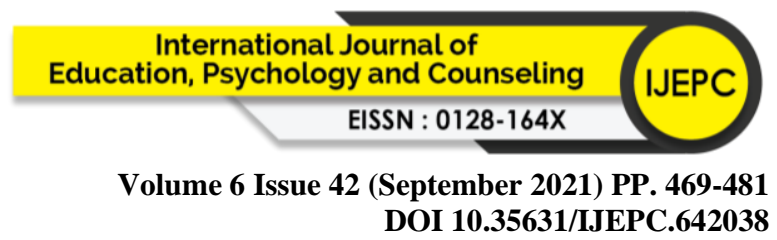

Empathic Feeling and Expression dimension have been reported to have highest internal consistency than other dimensions based on the Cronbach Alpha from the previous studies (e.g. Wang et al., 2003; Peifer, Lawrence, Williams \& Leyton-Armakan, 2016) which was 0.90. The Empathic Perspective Taking dimension was reported to have a good internal consistency which was 0.79 followed by the Acceptance of Cultural Differences dimension which was 0.71 and lastly Empathic Awareness which was 0.74 (Wang et al., 2003). Respondents gave their answers based on a 6-point of Likert-like scale where $1=$ strongly disagree that it describes me and $6=$ strongly agree that it describes me.

\section{Organizational Citizenship Behavior (OCB)}

OCB was measured using Lee and Allen's (2002) 16-items OCB scale which has two dimensions. The first dimension is organizational citizenship behavior directed to organization $(\mathrm{OCBO})$ - discretionary behaviors that the goal is to benefit the organization (such as improving organizational image and performance). An example of the item measuring OCBO is "Offer ideas to improve the functioning of the organization." The second dimension is organizational citizenship behavior directed to individuals (OCBI) - discretionary behavior that benefits specific individuals and indirectly contributes towards organizational success (such as helping and assisting fellow employees who have been absent). An example of the item measuring OCBI is "Willingly give your time to help others who have work-related problems."

Each of these dimensions reported good internal consistency reliability (Cronbach Alpha) with OCBO $\alpha=0.88$, and OCBI $\alpha=0.83$ (Lee \& Allen, 2002). The respondents will answer on a 7point Likert-like scale ranging from $1=$ never to $7=$ always.

\section{Procedures}

A formal letter was sent to the Main Headquarters of the National Registration Department (JPN) situated in Kota Kinabalu, Sabah as to acquire permission to do a study on the selected branches of JPN Sabah from the Director of National Registration Department Sabah, YBhg. Dato' Ismail bin Ahmad. After the approval was given, the main headquarters of Sabah's JPN would inform all of the selected heads of the branch that a survey would be distributed to the JPN's employees at the selected branches around Sabah. The Malay version of the questionnaire was distributed to respondents from the selected branches. A token of appreciation was given to the respondents who participate in the survey to appreciate the cooperation given and to increase the likelihood of a high returning rate of questionnaires.

\section{Data Analysis}

The data were analyzed using partial least square-structural equation modeling (PLS-SEM) with the Smart PLS 3 program (Ringle, Wende \& Becker, 2015). This was due to the violation of data distribution in normality testing whereby the variables in question showed a P-value smaller than 0.05 in the Shapiro-Wilks test. This study used a reflective measurement model and therefore would be evaluated and reported based on its internal consistency reliability, convergent validity, and discriminant validity. When the measurement model has been validated successfully, then the evaluation would move to the structural model in which the evaluation is based on the $\mathrm{R}^{2}$ explained variance and path coefficients. 


\section{Results}

\section{Measurement Model}

\section{Internal Consistency Reliability $(\mathrm{CR})$}

The results showed that each construct in ethnocultural empathy dimensions as well as organizational citizenship behavior dimensions have fulfilled the acceptable value of composite reliability. According to Hair, Hult, Ringle \& Sarstedt, (2017), the acceptable threshold value of composite reliability for a measurement model is between 0.60 to 0.90 . Therefore, the items used to represent the construct have satisfactory internal consistency reliability. Table 1.0 shows the value of composite reliability for each construct for this study which ranges between 0.91 to 0.75 .

\section{Convergent Validity (AVE)}

The results showed average variance extracted (AVE) for ethnocultural empathy's dimensions are as follow, (1) acceptance of cultural difference (ACD) is $0.54,(2)$ empathy awareness (EA) is 0.57 , (3) empathy feeling and expression (EFE) is 0.55 and (4) empathy perspective-taking is 0.50. Meanwhile, the AVE for OCB's dimensions are as follows, (1) organizational citizenship behavior-individual (OCB-I) is 0.52 and (2) organizational citizenship behaviororganization (OCB-O) is 0.59 . Therefore, all constructs in this study have the value of AVE ranges between 0.50 to 0.59 which fulfilled the recommended threshold value as mentioned by Hair Ringle \& Sarstedt, (2017).

Table 1.0: Composite Reliability

\begin{tabular}{ccc}
\hline Variable & Construct & Composite Reliability \\
\hline & Acceptance of Cultural Difference & 0.82 \\
(ACD) & 0.80 \\
Ethnocultural & Empathy Awareness (EA) & 0.83 \\
& Empathy Feeling and Expression & 0.75 \\
\hline Organizational & Empathy Perspective Taking (EPT) & 0.87 \\
Citizenship & OCB- Individual (OCBI) & 0.91 \\
\hline
\end{tabular}

\section{Divergent Validity (Fornell-Larcker Criterion)}

The next method used to examine discriminant validity is the Fornell-Larcker criterion. Based on Table 2.0, the result of the Fornell-Larcker criterion with the square root of the AVE of the reflective constructs showed on the diagonal position and the correlations between the constructs in the off-diagonal position. To determine the existence of discriminant validity in a model is the value of the AVE's square root should be higher than the construct's highest correlation with any other construct in the model (Hair, et. al., 2017). Based on the results shown in the table below, the square roots of the AVEs for the reflective constructs ACD (0.73), EA (0.75), EFE (0.74), EPT (0.70), OCBI (0.72), and OCBO (0.77) are all higher than the 


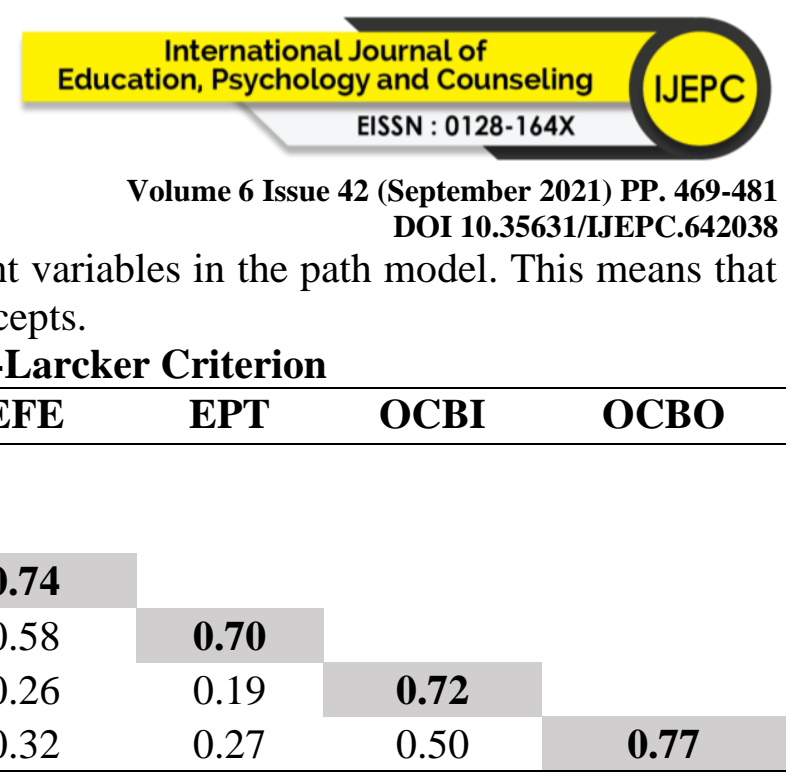

\section{Structural Model}

\section{Path Coefficient}

Using the results from the path assessment, the acceptance or rejection of the proposed hypotheses is determined. Based on the results, in ethnocultural empathy dimensions, empathy awareness dimension (EA) has a significant relationship with organizational citizenship behavior- Individual (OCBI), meanwhile empathic feeling \& expression dimension (EFE) has a significant relationship with organizational citizenship behaviour-Organization (OCBO). Table 3.0 lists down the path coefficients, t-statistics, and p-values which represent the significant level for all hypothesized paths.

Table 3.0: Path coefficients, $t$-statistics, and significant value

\begin{tabular}{clccc}
\hline Dependent Construct & $\begin{array}{c}\text { Independent } \\
\text { Construct }\end{array}$ & $\begin{array}{c}\text { Path } \\
\text { Coefficient } \\
(\boldsymbol{\beta})\end{array}$ & $\begin{array}{c}\text { T- } \\
\text { statistics }\end{array}$ & $\begin{array}{c}\text { Significant } \\
\text { Level }\end{array}$ \\
\hline \multirow{2}{*}{ OCBI } & $\leftarrow \mathrm{ACD}$ & 0.11 & 1.01 & 0.31 \\
$\left(\mathrm{R}^{2}=0.13\right)$ & $\leftarrow$ EA & $\mathbf{0 . 2 7}$ & $\mathbf{3 . 8 2}$ & $\mathbf{0 . 0 0}$ \\
& $\leftarrow \mathrm{EFE}$ & 0.11 & 1.23 & 0.22 \\
& $\leftarrow \mathrm{EPT}$ & 0.05 & 0.58 & 0.56 \\
\hline OCBO & $\leftarrow \mathrm{ACD}$ & -0.08 & 0.67 & 0.50 \\
$\left(\mathrm{R}^{2}=0.19\right)$ & $\leftarrow \mathrm{EA}$ & 0.03 & 0.45 & 0.65 \\
& $\leftarrow$ EFE & $\mathbf{0 . 2 0}$ & $\mathbf{2 . 2 2}$ & $\mathbf{0 . 0 3}$ \\
& $\leftarrow \mathrm{EPT}$ & 0.14 & 1.45 & 0.15 \\
\hline
\end{tabular}

\section{Coefficient of Determination ( $\boldsymbol{R}^{2}$ value)}

Referring to Table 3.0, ethnocultural empathy dimensions (ACD, EA, EFE, and EPT) are able to explain $13 \%$ of the variance in OCBI, meanwhile explained $19 \%$ of the variance in OCBO. Based on the rule of thumb provided by Hair, and colleagues (2017), the $\mathrm{R}^{2}$ value of OCBI and OCBO are rather weak.

\section{Discussion}

The results showed that empathy feeling \& expression (EFE) and empathy awareness (EA) have significant relationships to organizational citizenship behavior (OCB). In general, it can be concluded that individuals who have high empathy have the tendency to engage in prosocial Copyright $\odot$ GLOBAL ACADEMIC EXCELLENCE (M) SDN BHD - All rights reserved 


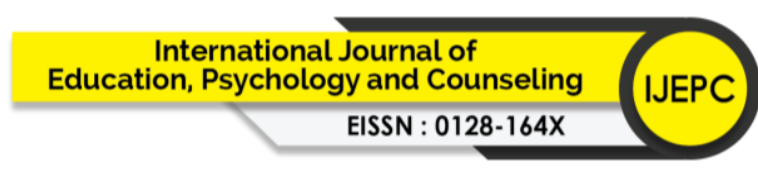

Volume 6 Issue 42 (September 2021) PP. 469-481

DOI 10.35631/IJEPC.642038

behaviors such as helping others in need. The connection between empathy and prosocial behaviors can be traced back to the study of Mehrabian and Epstein (1972) where they found that empathy was the primary predictor for helping behaviors. This result was supported later in Batson, Duncan, Ackerman, Buckley \& Birch (1981) study when they found out that empathy leads to altruistic motivation to help. Moreover, Batson and colleagues had done extensive reviews on the empathy-altruism hypothesis and concluded that altruism can be generated by empathy (Batson, Lishner \& Stock, 2015). Nevertheless, empathy without having the knowledge or experience with people from different backgrounds especially those who are from different cultures may interfere with the helping behaviors thus increasing the level of unsatisfying delivery of services among professionals (Rasoul, Eklund \& Hansel, 2011). By practicing ethnocultural empathy, a person will try to offer help to another person not on the basis of our own's feelings and thought but making sure to include and understand the culture that shapes the feeling and thought of other persons.

\section{Empathic Feeling \& Expression (EFE) and Organizational Citizenship Behavior- Organization (OCBO)}

By relating to four dimensions in the Scale of Ethnocultural Empathy (SEE), the empathic feeling \& expression (EFE) dimension has a significant relationship with OCB-O (organization). According to Wang and colleagues (2003), EFE is the expression of empathy that focus on the emotional or affective responses to emotions or/and experience of other that come from different racial/ethnic groups. The expression of empathy can be in the form of thoughts, feelings, words, and actions that relate directly to the discriminatory experiences (Wang, et. al., 2003). In other words, empathy is induced based on an individual's experiences of discrimination regarding his or her ethnicity and therefore refuse or avoid to create the same experiences onto the other people of different ethnicity whether in the form of thoughts, feelings, words, and actions.

When relating to the Malaysian context especially in Sabah, there are approximately 33 ethnic groups who communicate in 80 ethnic dialects (Laman Web Rasmi Kerajaan Negeri Sabah, 2021) thus open to multicultural diversity experiences. In the organizational context, JPN employees in Sabah need to deliver formal services to multicultural society therefore, have a tendency to practice EFE throughout their services whether to the society or to the fellow employees. The result is supported by a study done by Atkins, Uskul, and Cooper (2016), where they found that East Asians have a higher tendency to behave based on the cultural expectation that aligns with others' emotional states in order to achieve and maintain interpersonal harmony. This means that individuals with EFE try to feel what other people felt and disagree in any form of discrimination of other ethnic groups by imagining placing themselves in such a discriminatory position (Taufik, 2019).

In regards to OCBO, it is a form of discretionary behaviors that the goal is to benefit the organization such as improving organizational image or being proud to be part of the organization (Lee \& Allen, 2002). The connection of EFE to OCBO is somehow contradictory to the findings of previous studies which stated that OCBO is related more towards job cognitions rather than dispositional variables such as empathy (Lee \& Allen, 2002; McNeely \& Meglino,1994). Though the connection of both variables was weak in the previous studies, however, the connection to OCBO is established when empathy is embedded with culture. This was supported by a study done by Taufik (2019) where he stated that emotion matching was established in order to feel similar emotion as what other people feel. Therefore, aligning with 


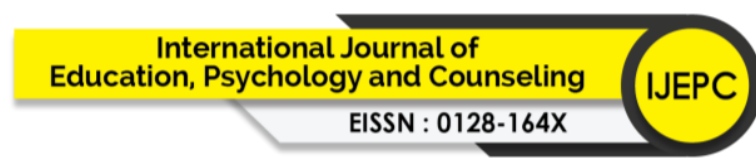

Volume 6 Issue 42 (September 2021) PP. 469-481

DOI 10.35631/IJEPC.642038

others' emotional states that come from different backgrounds leads to the establishment of interpersonal harmony (Atkins, et. al., 2016) in the act of benefiting the organization such as loyalty and avoiding conflicts which can negatively drag the organization image.

In support of this argument, a study was done by Miranda-Diaz, Clark-Shim, Keller, and Spencer (2020) showed that individuals who implanted empathy with culture would try to create a sense of belonging in their groups even though the members are coming from different ethnicity and cultures. This means that individuals who practice EFE would avoid any conflicts with regards to discrimination, prejudice, and stereotyping as they understand the feeling of such would destroy the harmony thus cannot function as one unit in the organization. With the nature of the National Registration Department's (JPN) workload dealing with citizenship registration such as birth, death, marriage as well as divorce registration, JPN is considered as one of the important frontline public agencies dealing with society. According to Paillé, Grimma, and Dufour (2015), civil service caters to the needs and well-being of the public through giving services and cares for the people. With JPN's slogan "Rakyat di Hati JPN", it is important for every JPN's employee not only to have excellent job skills to perform the jobrelated tasks but also to have another set of humanizing skills such as empathy, courtesy, altruism, and helpful behaviors in giving the best services to the society as well as to uphold a positive organizational image.

\section{Empathic Awareness (EA) and Organizational Citizenship Behavior-Individual (OCBI)}

One of the dimensions in SEE is empathic awareness (EA). The dimension tends to focus on the awareness or knowledge that an individual has about experiences of people from racial or ethnic groups different from one's own (Taufik, 2019). However, according to Taufik (2019), one must understand and be aware of one's own culture first (self-awareness) so that the differences of cultures may produce acknowledgment and respect for one another. This is also supported by Bockler, Hermann, Trautwein, Holmes, and Singer (2017), where they found that individuals who are able to establish empathy are those who are capable to understand themselves in terms of patterns of attitudes and behavior. Moreover, self-awareness of our own culture helps to improve individual relationships with others despite differences. Sometimes empathic awareness is evoked by the experience of discrimination or unequal treatment of different groups (Wang, et. al., 2003). This was supported by Fix (2020) who stated that those individuals who have a higher level of empathic awareness were much more aware of racial discrimination and oppression. Moreover, empathy is seen as a crucial element to increase cultural competencies as it can increase awareness on institutional racism (Lee, Neville, Schlosser, Valgoi \& Cha-Jua, 2021). Therefore, watching or hearing discrimination about other ethnic groups can somehow make individuals alert thus avoiding of such incidents to reoccur.

In regards to OCBI, it is a form of discretionary behavior that benefits specific individuals and indirectly contributes towards organizational success (Lee \& Allen, 2002). The finding of this study is aligning with the previous studies where empathy has a connection with OCBI (Lee \& Allen, 2002; McNeely \& Meglino,1994). It has been discovered in a study done by Settoon and Mossholder (2002) that there was a relationship between empathy and interpersonal citizenship behavior whereby the citizenship behavior was directed to individual context such as helping other employees. Similiarly, Allen, Facteau, and Facteau (2004) suggested that empathy influenced organizational citizenship behavior but towards individual context (OCBI). 


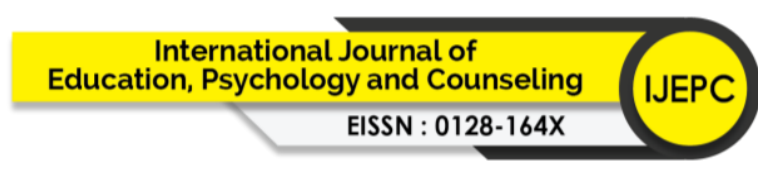

Volume 6 Issue 42 (September 2021) PP. 469-481

DOI 10.35631/IJEPC.642038

In a like manner with empathic awareness (EA) to OCBI, employees are able to provide aids to their colleagues without neglecting cultural differences. The finding is supported by a study that focuses on program-based mentoring which involved cross-cultural relationships (Peifer, Lawrence, Williams \& Leyton-Armakan, 2016). The study reported that mentors who practicing ethnocultural empathy tend to have higher levels of altruistic motivations for volunteering (Peifer, et. al., 2016). In this case, despite cultural differences and diverse ethnicity in the program, mentors who understand and are aware of these differences were ready to embark on the process of helping and support their mentees in the mentoring program.

In Malaysia, ethnocultural empathy is a crucial concept for employees to practice especially when they are from multi-ethnicity backgrounds working together to achieve the same organizational goals. Therefore, supporting one another regardless of different races and ethnicity is seen crucial to foster and maintain an organizational social system. Moreover, according to Miranda-Diaz, Clark-Shim, Keller, and Spencer (2020), ethnocultural empathy is able to enhance the quality of life of other individuals regardless of ethnicity. For example, issues such as job rotation or requesting to substitute employees who are taking days off from work especially during festive seasons can be bothersome to some employees. They need to reschedule their working days, adding up their duties and even sacrificing their own holiday in doing so. However, with empathy awareness (EA), employees are aware that they are working with colleagues of different ethnic backgrounds who celebrating diverse celebrations and so, broaden their perspectives in seeing things. As Peifer Lawrence, Williams \& Leyton-Armakan (2016) mentioned that when individuals practice ethnocultural empathy, they are motivated and even volunteering to help others therefore, these employees would act in courtesy to substitute their colleagues in leave and indirectly enhance the quality of life of others.

\section{Suggestion for Future Research}

This study is based on the empathy-altruism hypothesis discussed by Batson, Duncan, Ackerman, Buckley, and Birch (1981) as a basic guideline to explain the concept of empathy that leads to altruistic/ helping behavior. In view of Batson's empathy-altruism hypothesis, empathy is viewed as something related to affective responding in which empathy is related to observers' emotional responses toward others' emotional states, experiences, and welfare (Batson, Turk, Shaw \& Klein, 1995). Therefore, in this approach, empathy is seen as the main motivator in helping others in need.

Though this approach explains motivation in helping others and justifies the prosocial motivation, however, it lacks to explain empathy in cultural context especially in a multiethnicity society. By examining the concept of ethnocultural empathy hopes to expand the empathy-altruism hypothesis approach to a greater understanding of empathy in culture and its effects on altruistic behaviors. Future research could examine the concept of ethnocultural empathy by incorporating other variables that lead to altruistic behaviors in larger crosscultural society as well as investigating the antecedents of ethnocultural empathy.

Apart from that, this study used a cross-sectional survey to investigate variables in question therefore exploration of the variables is limited. For future study, qualitative research could be used to explore in-depth the concept of ethnocultural empathy-altruistic behaviors, especially in the organizational context. Interviewing the respondents could open up possibilities of connections that can create a new hypothetical model thus adding the existing knowledge of the variables in question. 


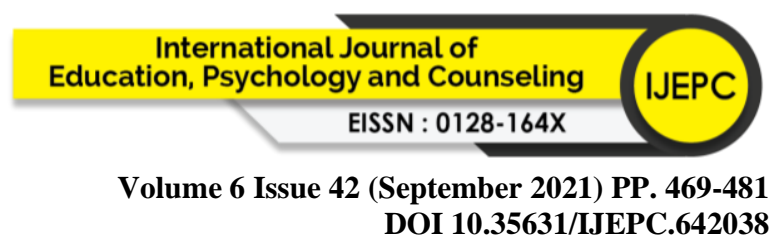

\section{Conclusion}

An organization should not only focus on the accomplishment of the in-role performance but also on building the social system that serves as a core function to connects its members in order for the organization to function effectively. For this reason, the extra-role performance such as OCB should not be neglected, as many pieces of evidence showed OCB is indirectly supporting existing formal behaviors thus helping an organization to function efficiently (Basu, Pradhan, \& Tewari, 2017; Lavy \& Littman-Ovadia, 2016; Noorlaila Yunus \& Cairul Azwa Azimi, 2016; Subramaniam Sri Ramalu \& Zulhusni Mohamad Rashid, 2016). Therefore, it is important to understand antecedents such as empathy that can lead to OCB practices among employees. Evidence can be seen in studies throughout time which reported that people with empathic ability influence helping behavior regardless of everyday context or professional context (Peifer, Lawrence, Williams \& Leyton-Armakan, 2016; Rasoul, Eklund, \& Hansen, 2011; Allen, Facteau \& Facteau, 2004; McNeely \& Meglino, 1994). As OCB can be considered as a form of helping behavior in the organization, it is possible to examine the connection between these variables. In fact, empathy is described to mitigate intolerance and conflicts by increasing individuals' understanding and tolerance thus respecting other people. In the organizational context, employees who have empathy were willing to help other fellow employees in their job duties and tasks even providing a better quality of services to the society. As social interaction and prosocial behaviors do not limit to a particular group of people within the same race and ethnicity, there is a need to broaden the concept of empathy which can be applied in social interaction with different ethnicity and culture. Malaysia is a country of melting pot where vast ethnicity is living together. Moreover, in the organizational context, employees with different backgrounds are working together to achieve the same organization's mission. The practice of ethnocultural empathy helps individuals to understand not only the feeling and thinking of others but also aware of the action and communication that relate directly to other individuals from a different culture. Therefore, ethnocultural empathy can be one of the antecedents to promote or cultivate employees in OCB thus maintaining interpersonal harmony.

\section{References}

Allen, T. D., Facteau, J. D., \& Facteau, C. L. (2004). Structured interviewing for OCB: Construct validity, faking, and the effects of question type. Human Performance, 17(1), $1-24$.

Atkins, D., Uskul, A. K., \& Cooper, N. R. (2016). Culture shapes empathic responses to physical and social pain. Emotion, Vol. 16, No. 5, 587-601

Basu, E., Pradhan, R. K., \& Tewari, H. R. (2017). Impact of organizational citizenship behaviour on job performance in Indian healthcare industries. International Journal of Productivity and Performance Management, 66(6), 780-796.

Batson, C. D., Duncan, B. D., Ackerman, P., Buckley, T. B., \& Birch, K. (1981). Is empathic emotion a source of altruistic motivation? Journal of Personality and Social Psychology, Vol. 40, No. 2, 290-302.

Batson, C. D., \& Shaw, L. L. (1991). Evidence of altruism: Toward a pluralism of prosocial motives. Psychology Inquiry, Vol. 2, No. 2, 107-122.

Batson, C. D., Turk, C. L., Shaw, L. L., \& Klein, T. R. (1995). Information function of empathic emotion: Learning that we value the other's welfare. Journal of Personality and Social Psychology, Vol.68, No.2, 300-313.

Batson, C. D., Lishner, D. A., \& Stock, E.L. (2015). The empathy-altruism hypothesis. The Oxford handbook of prosocial behavior. 259-281. 


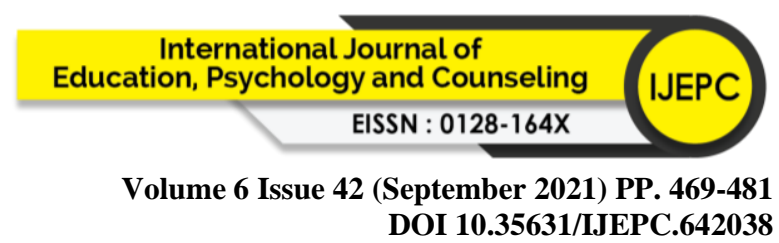

Bockler, A., Hermann, L., Trautwein, F.M., Holmes, T., \& Singer, T. (2017). Know thy selves: Learning to understand oneself increases the ability to understand others. J Cogn Enhanc 2017; 1(2): 197-209.

Cavana, R. Y., Delahaye, B. L., \& Sekaran, U. (2001). Applied business research: qualitative and quantitative methods. New York: John Wiley \& Sons, Inc.

Fix, R. L. (2020). Justice is not blind: A preliminary evaluation of an implicit bias training for justice professionals. Race and Social Problems, 1-13.

Hair, J. F., Hult, G. T. M., Ringle, C. M., \& Sarstedt, M. (2017). A primer on partial least squares structural equation modelling (PLS-SEM). Los Angeles: Sage.

Ibrahim, R., Aziz Amin, A., Ghani, M. A., Hashim, N., \& Salleh, M. (2015). Organisational citizenship behaviour readiness: A demographic study on local government employees in Southern Region of Malaysia. Pertanika J. Soc. Sci. \& Hum, 23(S): 51-62.

Junn, E.N., Morton, K. R., \& Yee, I. (1995). The "Gibberish exercise: Facilitating emphatic multicultural awareness. Journal of Instructional Psychology, 22, 324-329.

Krejcie, R. V., \& Morgan, D. W. (1970). Determining sample size for research activities. Educational and Psychological Measurement. 30, 607-610.

Lam, C. F., Wan, W. H., \& Roussin, C. J. (2016). Going extra mile and feeling energized: An enrichment perspective of organizational citizenship behaviours. Journal of Applied Psychology, Vol.101, No.3, 379-391.

Laman Web Rasmi Kerajaan Negeri Sabah. (2021). Retrieved August, 2021, from https:// https://www.sabah.gov.my/cms/?q=ms/content/rakyat-sejarah

Lavy, S., \& Littman-Ovadia, H. (2016). My Better Self: Using Strengths at Work and Work Productivity, Organizational Citizenship Behaviour, and Satisfaction. Journal of Career Development, 0894845316634056.

Lee, B. A., Neville, H. A., Schlosser, M., Valgoi, M. J., \& Cha-Jua, S. K. (2021). Ethnocultural empathy and racial colorblindless among white police recruiters: Do cross-racial friendships matter? Race and Justice, 1-22.

Lee, K., \& Allen, N. J. (2002). Organizational citizenship behaviour and workplace deviance: The role of affect and cognitions. Journal of Applied Psychology, Vol.87, No. 1, 131142.

McNeely, B. L., \& Meglino, B. M. (1994). The role of dispositional and situational antecedents in prosocial organizational behaviour: An examination of the intended beneficiaries of prosocial behaviour. Journal of Applied Psychology, Vol. 79, No. 6, 836-844.

Mehrabian, A., \& Epstein, N. (1972). A measure of emotional empathy. Journal of Personality, 40, 525-543.

Miranda-Diaz, M., Clark-Shim, H., Keller, T. E., \& Spencer, R. (2020). Determinants of motivation for mentoring among volunteering to mentor youth. Journal of Youth Development, Vol. 15, Issue 4, 174-189.

Noorlaila Yunus \& Cairul Azwa Azimi. (2016). The influence of Herzberg's motivator factor on employees' organizational citizenship behaviour. Advances in Business Research International Journal, Volume 2, No. 1, 1-13.

Organ, D. W. (1997). Organizational citizenship behaviour: It's construct clean-up time. Human Performance, 10(2), 85-97.

Peifer, J. S., Lawrence, E. C., Williams, J. L., \& Leyton-Armakan, J. (2016). The culture of mentoring: Ethnocultural empathy and ethnic identity in mentoring for minority girls. Cultural Diversity and Ethnic Minority Psychology, Vol. 22, No. 3, 440-446.

Raman, P., Sambasivan, M., \& Kumar, N. (2016). Counterproductive work behaviour among frontline government employees: Role of personality, emotional intelligence, 


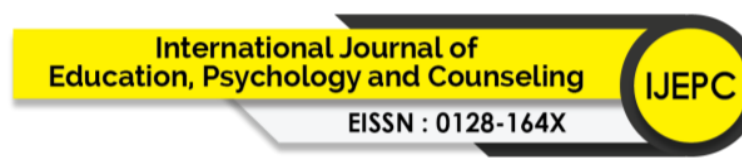

Volume 6 Issue 42 (September 2021) PP. 469-481 DOI 10.35631/IJEPC.642038

affectivity, emotional labor, and emotional exhaustion. Revista de Psicologia Del Trabajo Y de Las Organizaciones, 32(1), 25-37. https://doi.org/10.1016/j.rpto.2015.11.002.

Rasoal, C., Eklund, J., \& Hansen, E. M. (2011). Towards a conceptualization of ethnocultural empathy. Journal of Social, Evolutionary, and Culture Psychology, 5(1), 1-13.

Ringle, C. M., Wende, S., \& Becker, J-M. (2015). SmartPLS 3. Boenningstedt: SmartPLS $\mathrm{GmbH}, \mathrm{http}: / /$ www.smartpls.com.

Sample Size Calculator by Raosoft. (2017). Retrieved August 19, 2017, from www.raosoft.com/samplesize.html.

Settoon, R. P., \& Mossholder, K. W. (2002). Relationship quality and relationship context as antecedents of person-and task-focused interpersonal citizenship behaviour. Journal of Applied Psychology, 87, 255-267.

Sirin, C. V., Valentino, N. A., \& Villalobos, J. S. (2016). Group empathy in response to nonverbal racial/ethnic cues. A national experiment on immigration policy attitudes. American Behavioural Scientist, Vol 60(14), 1676-1697.

Subramaniam Sri Ramalu \& Zulhusni Mohamad Rashid. (2016). Islamic work ethic and organizational citizenship behaviour: a study among civil servants in Malaysia. South East Asia Journal of Contemporary Business, Economics and Law, 11(2).

Taufik, T. (2019). Ethnocultural empathy in a pluralistic society: Inter-ethnic relationships of Javanese and Chinese children in Surakarta. The Open Psychology Journal, 12(1), 95 101.

Wang, Y-W., Davidson, M. M., Yakushko, O. F., Savoy, H. B., Tan, J. A., \& Bleier, J. K. (2003). The scale of ethnocultural empathy: Development validation and reliability. Journal of Counseling Psychology, Vol 50, No. 2, 221-234.

Wei, M., Li, C-I., Wang, C., \& Ko, S. Y. (2016). Finding benefits from acculturative stress among Asian Americans: Self-reflection moderating the mediating effects of ethnocultural empathy on positive outcomes, Journal of Counselling Psychology, 63 (6), 633-644. 